
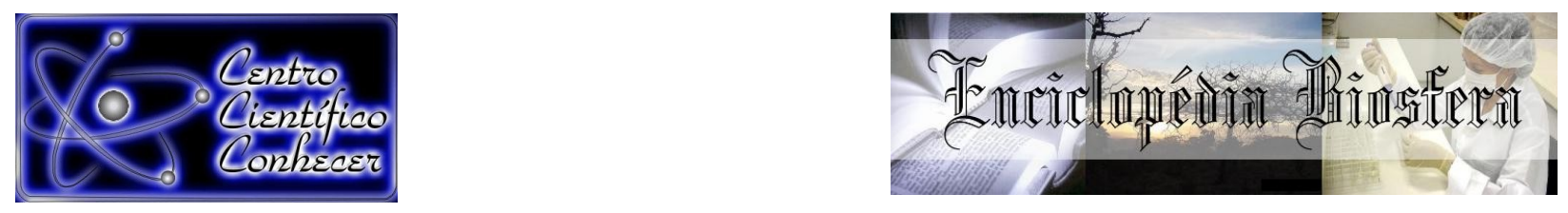

\title{
ANÁLISE ECONÔMICA DA IMPLANTAÇÃO DE SOJA COM SUCESSÃO DE MILHO E ILP EM UMA PROPRIEDADE RURAL NO MUNICÍPIO DE ORIZONA, GOIÁS
}

\section{Marcos Vinicios Faleiro ${ }^{1}$, Daniela Gonçalves Rosa ${ }^{1}$, Luciana Maria da Silva ${ }^{1}$, Andrécia Cósmem da Silva ${ }^{2}$ Matheus da Silva Araújo ${ }^{3}$}

${ }^{1}$ Discentes do Curso de Agronomia da Universidade Estadual de Goiás, Campus Ipameri, Ipameri, GO, Brasil. (marcos-viniciosf@hotmail.com)

${ }^{2}$ Professora mestre da Universidade Estadual de Goiás, Campus Ipameri, Ipameri, GO, Brasil

${ }^{3}$ Mestrando do Curso de Pós-Graduação em Ciências Florestais da Universidade de Brasília, Campus Darcy Ribeiro, Brasília, DF, Brasil

Recebido em: 08/04/2017 - Aprovado em: 10/06/2017 - Publicado em: 20/06/2017 DOI: 10.18677/EnciBio_2017A9

\begin{abstract}
RESUMO
Objetivou-se neste estudo avaliar a viabilidade econômica da implantação do sistema Integração Lavoura Pecuária do cultivo de soja com sucessão de safrinha de milho em uma propriedade rural no município de Orizona, Goiás. Para a análise de viabilidade econômica utilizou os indicadores econômicos: Relação BenefícioCusto (RBC), Valor Presente Líquido (VPL) e Tempo de Recuperação do Investimento (Pay Back atualizado), com taxa de juros de 10\%, durante um período de análise do projeto de 5 anos. Obteve-se um custo total para a implantação do projeto de $R \$ 3.797 .782,40$, enquanto que a receita atingiu $R \$ 4.881 .595,48$, obtendo lucro líquido de $\mathrm{R} \$ 1$ 1.083.813,07. O tempo de retorno para o capital investido foi obtido no $9^{\circ}$ mês e a razão RBC apresentou índice de 1,29. Tal fato está relacionado com o baixo investimento na implantação do projeto, uma vez que, a propriedade possui patrimônio já existente e por desenvolver outras atividades permitindo retorno financeiro. Assim a implantação do projeto na propriedade estudada é viável.
\end{abstract}

PALAVRAS-CHAVE: Gado de corte, produção de grãos, viabilidade.

\section{ECONOMIC ANALYSIS OF SOYBEAN IMPLANTATION IN SUCCESSION OF CORN AND ILP IN A RURAL PROPERTY IN THE ORIZONA MUNICIPALITY, GOIÁS}

\begin{abstract}
The objective of this study was to evaluate the economic viability of a TillageLivestock Integration system implantation, where the soybean crop is in succession to the corn crop in a rural property in the Orizona municipality, Goiás. For the economic feasibility analysis, we used the economic indicators: Benefit-Cost Ratio (RBC), Net Present Value (NPV), and Investment Recovery Time (updated Payback), with an interest rate of $10 \%$, during the analysis period of the 5-year project. There was a total cost of $\mathrm{R} \$ 3,797,782.40$ for the project implantation, while revenue reached $R \$ 4,881,595.48$, and net income of $R \$ 1.083,813.07$. The return


time of the invested capital was obtained in the 9th month, and the RBC ratio had an index of 1.29. This fact was related to the low investment in the project implantation since the property already had assets for the development of other activities, allowing the financial return. So the project implantation in the property studied was feasible.

KEYWORDS: Beef cattle, grain production, viability.

\section{INTRODUÇÃO}

O Brasil ao longo das últimas décadas vem se consolidando como grande produtor no setor agropecuário, contribuindo significativamente na economia nacional e proporcionando uma posição de destaque no cenário mundial (FERNANDES \& FINCO, 2014). Dentre os biomas brasileiros, o Cerrado apresenta grande destaque no cenário do agronegócio brasileiro, principalmente na produção de grãos e carne do país. (GARCIA et al., 2013).

No entanto com a intensificação dos recursos produtivos, e a preocupação com o meio ambiente, tem-se levado a produtores e pesquisadores a busca por alternativas mais econômicas e sustentáveis (GLÉRIA et al., 2017). Porém, são comuns em propriedades rurais, principalmente no bioma Cerrado, o desenvolvimento do monocultivo, atividade que apresenta risco, uma vez que está susceptível a fatores internos e externos reduzindo assim o faturamento da propriedade (CORDEIRO et al., 2015).

A alternativa mais adequada é o uso de um sistema sustentável, que utiliza intensamente os recursos disponíveis. Nesse sentido, a Integração lavoura-pecuária (ILP) pode contribuir significativamente, em função de sua diversidade de produção, obtendo produtos advindos tanto da agricultura quanto da pecuária, proporcionando a redução de custos e o aumento de produtividade (GARCIA et al., 2013; CORDEIRO et al., 2015). Outro sistema de produção importante é a diversificação de culturas que ocorre no cultivo de soja verão, seguido pelo plantio de milho safrinha. O Brasil está entre os países mais produtores destas culturas, sendo esta produção concentrada no Cerrado (TORRES et al., 2014).

O Sistema ILP explora de forma mista culturas agrícolas e pecuárias, sendo caracterizada pela diversificação, consorciação, rotação, e/ou sucessão de atividade de agricultura e pecuária (SANTOS et al., 2011). Uma de suas principais vantagens é o fato do solo ser ocupado durante todo o ano ou grande parte dele, o que favorece a oferta de grão e carne a um custo reduzido (GONÇALVES \& FRANCHINI 2007; SILVA et al., 2015).

A ILP consiste também num sistema de produção no qual ambos se beneficiam por melhorar as características químicas, físicas e biológicas do solo, aumentando a lucratividade do produtor (CUSTÓDIO et al., 2015). Já no cultivo de soja e safrinha de milho, observa-se viabilidade nesse sistema visto que a diversificação de cultivo proporciona aumento na palhada e redução de pragas e doenças, além de permitir melhor otimização da área (SORATTO et al., 2010).

Observa-se que a diversificação das atividades possibilita redução dos riscos de produção e uma maior rentabilidade nos negócios, assim o produtor não depende financeiramente apenas de um único produto, podendo de tal modo compensar os custos quando não atingir o retorno financeiro lucrativo (MOREIRA et al., 2011). Deste modo, é de extrema importância estudos relacionados a perspectivas econômicas, que garantem o sucesso do empreendimento (ZAGO et al., 2009). Ademais, é bom salientar que poucas são as informações direcionadas a viabilidade econômica dos projetos agrícolas (FERRAZA et al., 2016). 
A avaliação econômica de um investimento compreende critérios de análises e uso de técnicas que confrontam as receitas e custos visando conferir a viabilidade da implementação de projetos. Assim, na análise de rentabilidade o levantamento dos custos de produção agrícola permite analisar a lucratividade, a rentabilidade e a eficiência do sistema de produção implantado pelo produtor rural. Este conhecimento é de relevância em uma atividade econômica, independente do tamanho, do ramo de atuação ou sistema de produção explorado. Deste modo, o estudo técnico possibilita um desenvolvimento de uma agricultura competitiva e autossustentável (RICHETTI, 2016).

Assim, fazem-se necessários estudos de viabilidade econômica para implantação de projetos agropecuários, garantindo a consistência e a rentabilidade dos empreendimentos. Diante do exposto, o presente estudo teve por objetivo avaliar a viabilidade econômica da implantação do cultivo de soja com sucessão a safrinha de milho e o sistema ILP em uma propriedade no município de Orizona, Goiás.

\section{MATERIAL E MÉTODOS}

A análise econômica do projeto foi realizado entre agosto à dezembro de 2016 para um horizonte de planejamento de 5 anos em uma propriedade rural no

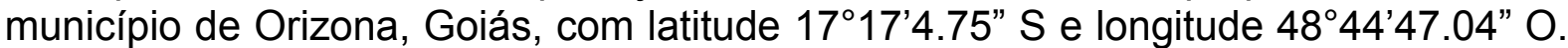
A região, segundo a classificação de Koppen apresenta clima Tropical Úmido (AW) com duas estações bem definidas, sendo verão quente e úmido e inverno frio e seco, a temperatura média da região é de $22,9^{\circ} \mathrm{C}$ (ALVARES et al., 2013).

A propriedade estudada possui área total de 198 ha, destes, 44,8 ha são destinados à reserva legal e o restante é ocupado com pastagem degradada. Deste modo, a área com pastagem foi subdividida para analisar a viabilidade em 100 ha do cultivo de soja verão seguida da safrinha de milho, e 45,2 ha para o sistema de Integração Lavoura-Pecuária (ILP).

Por meio de uma vistoria in loco, observaram-se os fatores internos e externos que influenciam a situação econômica da propriedade, analisando os pontos fortes e fracos e as oportunidades e ameaças, assim como a infraestrutura e quadro de funcionários. Em relação ao estudo de mercado observou-se a oferta, demanda e perspectivas de mercado para os grãos de soja, milho verão e safrinha, e para boi gordo (nelore), bem como os insumos e mão de obra temporária necessária para a implantação do projeto.

$\mathrm{Na}$ área agricultável destinada para implantação do projeto (145,2 ha) realizou-se a correção do solo, aplicando $2.500 \mathrm{~kg} / \mathrm{ha}$ de calcário dolomítico. Além deste, na área de ILP (100 ha), acrescentou-se $1.000 \mathrm{~kg}$ de gesso.

No cultivo da soja utilizou-se a cultivar 5909 RR (Nideira), que possui ciclo precoce (105 dias). Recomendou-se uma densidade de 25 sementes/metro linear, em profundidade de 0,5 $\mathrm{m}$, em espaçamento entre linhas de 0,45 $\mathrm{m}$. As sementes foram inoculadas, e recebeu-se adubação de plantio com $280 \mathrm{~kg} / \mathrm{ha}$ de MAP (11-5200 ), e com $150 \mathrm{~kg} / \mathrm{ha}$ de $\mathrm{KCl}$, em profundidade de $0,1 \mathrm{~m}$. No cultivo do milho, utilizou-se a variedade 2B433 PW (Dow), de ciclo de 140 dias. A semeadura foi executada após a colheita da soja, sendo esta com $0,5 \mathrm{~m}$ de profundidade com 3 sementes/metro, em espaçamento de $0,50 \mathrm{~m}$, assim atingindo uma população de 60.000 plantas/ha. Utilizou-se a adubação com $350 \mathrm{~kg} / \mathrm{ha}$ do formulado 10-20-15 e cobertura com $150 \mathrm{~kg} / \mathrm{ha}$ do formulado 36-00-12 e $15 \mathrm{~kg} / \mathrm{ha}$ de ureia. 
$\mathrm{Na}$ ILP, utilizou-se o milho 2B610 PW (Dow) com ciclo de 150 dias. A semeadura foi executada em uma profundidade de $0,5 \mathrm{~m}$, com 3,5 sementes/metro, e espaçamento de $0,50 \mathrm{~m}$, deste modo atingindo uma população de 70.000 plantas/ha. A adubação foi realizada com a aplicação de $450 \mathrm{~kg} / \mathrm{ha}$ do formulado 1020-15, seguido de uma cobertura de $508 \mathrm{~kg} / \mathrm{ha}$ de $36-00-12$. O adubo foi distribuído em uma profundidade de 0,1 m juntamente com a semente da Brachiaria brizantha cv. Marandu. Após 30 dias da colheita do milho grão, realizou-se o manejo de 90 cabeças de gado nelore sob a pastagem formada. Os animais foram adquiridos em leilão como boi magro (12 arrobas) e mantidos na área até o inicio da próxima safra de milho verão.

Os tratos culturais da área agricultável foram realizados com a aplicação de fungicidas, herbicidas, inseticidas, entre outros. E no rebanho fez-se a aplicação da vacinação obrigatória e a suplementação mineral.

Estimou-se uma produtividade das culturas conforme o manejo proposto e também estabeleceu os preços de vendas dos grãos por meio de levantamento em empresas da região. Determinou-se a produtividade por hectare e o preço da saca de $60 \mathrm{~kg}$ para os produtos colhidos, sendo: $48 \mathrm{sc} / \mathrm{ha}$ de soja, à $R \$ 72,30$; milho verão $143 \mathrm{sc} /$ ha à $R \$ 34,90$; e milho safrinha $120 \mathrm{sc} /$ ha por $R \$ 34,90$. Determinou para o gado nelore à venda em frigoríficos da região, onde aferiu uma produção de 190 cabeças, com peso final de $450 \mathrm{~kg}$, onde foram comercializados à $R \$$ 120,00/arroba.

Para a análise de viabilidade foram utilizados os indicadores financeiros: Relação Benefício/Custo (B/C), o Valor Presente Líquido (VPL) e Pay Back. Para a Relação Benefício/Custo (B/C) quando as receitas superarem as despesas, o projeto é considerado viável, isto é, a relação benefício/custo > 1 (COSTA et al., 2016).

$$
\text { Fórmula: } \quad \text { Relação } B / C=\frac{\sum_{j=0}^{n} R_{j} /(1+i)^{j}}{\sum_{j=0}^{n} C_{j} /(1+i)^{j}}
$$

Tem-se:

$$
\begin{aligned}
& \mathrm{Rj}=\text { receitas adquiridas no ano } \mathrm{j} \\
& \mathrm{I}=\text { taxa de desconto } \\
& \mathrm{Cj}=\text { custo adquiridos no ano } \mathrm{j} \\
& \mathrm{n}=\text { vida útil do projeto }
\end{aligned}
$$

O Valor Presente Líquido (VPL) se define em calcular os valores de todas as entradas e saída, sendo a somatória de todos os capitais oriundos das receitas produzidas, subtraído da soma das despesas ao longo da permanência do empreendimento, atualizados a partir da taxa de desconto do capital, adotado pelo investimento, dessa forma, um investimento será considerado viável se o VPL for positivo (LUCENA et al., 2016).

$$
\text { Fórmula: } \operatorname{VLP}=\sum_{j=0}^{n} R_{j}+(I+i)^{j}-\sum_{j=0}^{n} C_{j}+(I+i)^{j}
$$

Tem-se: 
$\mathrm{R}_{\mathrm{j}}=$ receitas adquiridas no ano $\mathrm{j}$

$\mathrm{C}_{\mathrm{j}}=$ custo do projeto no ano $\mathrm{j}$

$\mathrm{n}=$ vida útil do projeto

VPL $>0=$ o projeto é viável economicamente (Receita $>$ Custo);

VPL $<0=0$ projeto é inviável (Receita $<$ Custo);

VPL $=0=$ não há lucro, as receitas são suficientes para cobrir as despesas.

O Tempo de Recuperação do Investimento (Payback atualizado) demonstra o número de tempo necessário para que o fluxo de benefícios exceda o capital investido (BARRETO et al., 2012).

Fórmula: Pay back atualizado = Valor do Investimento

Valor dos fluxos de caixa

Os dados foram tabulados e calculados com a utilização do programa Excel. Os valores do fluxo de caixa foram atualizados com a taxa de desconto do capital de $10 \%$ a.a., sendo próximo à utilizada por SANTOS \& GRZEBIELUCKAS (2014).

\section{RESULTADO E DISCUSSÃO}

Os valores dos indicadores de rentabilidade utilizados foram aferidos a partir dos dados disponibilizados pelos coeficientes técnicos, dos rendimentos das atividades implantadas e do fluxo das despesas e receitas abarcadas no processo de introdução e manutenção do cultivo de soja com sucessão a safrinha de milho e o sistema ILP.

Os valores dos custos e receitas por hectare estão dispostos na Tabela 1. Onde os custos por hectare na implantação de soja com sucessão a safrinha de milho e no sistema ILP foram de $\mathrm{R} \$ 51.609,35$. Por outro lado obteve-se uma receita total de $\mathrm{R} \$ 70.099,57$, e valor presente líquido de $\mathrm{R} \$ 18.490,23$.

TABELA 1. Custos e Receitas da implantação de soja com sucessão de safrinha de milho e ILP por hectare em 5 anos.

\begin{tabular}{cc}
\hline \multicolumn{2}{c}{ Custos e receitas por hectare em 5 anos } \\
\hline Valor total de custo por ha & $\mathrm{R} \$ 51.609,35$ \\
Valor total de receita por ha & $\mathrm{R} \$ 70.099,57$ \\
Valor presente líquido por ha & $\mathrm{R} \$ 18.490,23$ \\
\hline
\end{tabular}

Conforme HELMERS \& SHAIK (2003), a diluição dos custos de manejo otimizando a infraestrutura é importante para o sucesso do empreendimento rural, como na utilização da integração e da sucessão de culturas. Deste modo é justificado o retorno financeiro na ILP e na soja com sucessão ao milho safrinha.

Analisando os empreendimentos separadamente no período de 5 anos, observa que o sistema de ILP em um hectare obteve um custo total de $\mathrm{R} \$ 12.862,06$ com uma receita de $R \$ 38.838,72$ e tendo um lucro total receita líquida de $R \$$ $25.976,66$. Já no cultivo de soja seguido de safrinha de milho por hectare, alcançouse um custo total de $R \$ 26.237,17$, receita de $R \$ 31.260,85$, obtendo uma receita líquida de $\mathrm{R} \$ 5.023,68$ (Tabela 2). 
TABELA 2. Custos e receitas da implantação dos empreendimentos por hectare em 5 anos: Soja com sucessão à safrinha de milho; Sistema de ILP.

Custo por hectare de ILP

\begin{tabular}{cc}
\hline Custo Total de Receita & $\mathrm{R} \$ 38.838,72$ \\
Custo Total da Despesa & $\mathrm{R} \$ 12.862,06$ \\
Receita Líquida & $\mathrm{R} \$ 25.976,66$ \\
\hline Custo por hectare da soja/milho safrinha \\
\hline Custo Total de Receita & $\mathrm{R} \$ 31.260,85$ \\
Custo Total da Despesa & $\mathrm{R} \$ 26.237,17$ \\
Receita Líquida & $\mathrm{R} \$ 5.023,68$ \\
\hline
\end{tabular}

De acordo com COIMBRA et al. (2015), o sistema ILP proporciona ao solo melhorias, permitindo aumento na eficiência dos insumos aplicados no sistema de produção, conferindo assim sustentabilidade à atividades, tanto para o milho verão quanto para a pastagem que irá sustentar o boi para engorda. PEDERSEN \& LAUER (2002) afirmam que a rotação de soja com milho safrinha, possibilita para ambas as culturas benefícios aumentando suas produções, isso quando comparado ao monocultivo. Deste modo os dados obtidos por estes autores corroboram com os valores alcançados para a implantação de soja com sucessão de safrinha de milho e sistema ILP (Tabela 3).

TABELA 3. Custos e receitas da implantação de soja com sucessão de safrinha de milho e sistema ILP em 145,2 hectares em 5 anos.

\begin{tabular}{cc}
\hline \multicolumn{2}{c}{ Tabela de custos em 145,2 hectares em 5 anos } \\
\hline Valor total de custos & $\mathrm{R} \$ 3.797 .782,40$ \\
Valor total da receita & $\mathrm{R} \$ 4.881 .595,48$ \\
Valor presente líquido & $\mathrm{R} \$ 1.083 .813,07$ \\
\hline
\end{tabular}

De acordo com as análises realizadas das atividades, todos os critérios se demonstraram viável economicamente conforme apresentado na tabela 4. Tais valores permitem observar a viabilidade econômica do projeto, esta justificada pelo fato do baixo investimento na implantação, uma vez que, a propriedade possui infraestrutura e também por desenvolver diferentes atividades permitindo retorno financeiro.

Estes resultados são reforçados quando comparado com os dados de COIMBRA et al. (2015), que na implantação do sistema ILP em sua avaliação econômica, também apresenta dados economicamente viáveis e ainda ressaltam a importância desta técnica por ser ambientalmente sustentável, minimizando problemas com ataque de pragas e doenças que afetam o sistema produtivo.

RICHETTI et al. (2016) quando analisaram a viabilidade econômica da cultura da soja na safra 2016/2017, em Mato Grosso do Sul, observaram dados significativos quando se obtém preços de mercado competitivos. O mesmo foi observado por RICHETTI (2015) ao analisar a viabilidade econômica do milho safrinha, sequeiro e irrigado, na Região Sul de Mato Grosso do Sul, para 2016. 
TABELA 4. Pay back e RB/C na implantação do sistema proposto e de suas atividades separadamente.

\begin{tabular}{cc}
\hline \multicolumn{2}{c}{ Soja com sucessão de safrinha de milho e sistema ILP } \\
\hline Pay Back & 9 meses \\
RB/C & 1,29 \\
\hline & Sistema de ILP \\
\hline Pay Back & 8 meses \\
RB/C & 1,05 \\
\hline
\end{tabular}

\begin{tabular}{cc}
\hline \multicolumn{3}{c}{ Soja e safrinha de milho } \\
\hline Pay Back & 10 meses \\
RBC & 1,19 \\
\hline O incentivo de estudos para a redução do monocultivo por meio de
\end{tabular}
instituições de ensino e pesquisa tem sido frequente. Assim, alternativas como a integração e rotação de culturas têm sido propostas, afim de que se tenha uma maior segurança no empreendimento rural, buscando viabilidade técnica e econômica.

A condução de pesquisas de viabilidade econômica na área de ILP e no plantio de soja seguido de safrinha de milho tem-se demonstrando ser uma importante ferramenta para os produtores, garantindo assim maior segurança na implantação de seus empreendimentos. Sendo assim, observa-se que, os produtores de Orizona/GO e região, possuem aspectos positivos e referenciais teórico para implantação dos sistemas de cultivo apresentado. Sendo importante, levar em consideração aspectos que podem ser decisivos no sucesso do investimento realizado, como: maquinário disponível para cultivo, preço estável dos grãos e do gado e ausência de condições climáticas adversas.

\section{CONCLUSÃO}

O cultivo de soja com sucessão de safrinha de milho e a implantação de sistema ILP, para as condições estabelecidas apresentou desempenho econômico satisfatório, a medida que, os indicadores de rentabilidade econômicos Relação B/C, VPL e Pay Back, foram positivos considerando o horizonte de planejamento avaliado.

Os estudos econômicos são uma importante ferramenta para os produtores na tomada de decisão em relação à implantação do cultivo de soja com sucessão de safrinha de milho e a implantação de sistema ILP, sendo uma ótima opção aos produtores rurais que buscam investimentos de riscos reduzidos e retornos financeiros.

\section{REFERÊNCIAS}

ALVARES, C.A.; STAPE, J.L.; SENTELHAS, P.C.; GONÇALVES, J.L.M.; SPAROVEK, G. Köppen's climate classification map for Brazil. Meteorologische Zeitschrift. $\quad$ v. 22, n. 6 , p. 711-728, 2013. Disponível em: https://doi.org/10.1127/0941-2948/2013/0507. Doi: 10.1127/0941-2948/2013/0507. 
BARRETO, E. L.; DA SILVA, R. C; VIEIRA, V. H. G.; PENA, H. W. Análise de viabilidade econômica: um estudo aplicado a estrutura de custo da cultura do açaí no estado do Amazonas. Observatório de La Economía Latinoamericana, n. 161, 2012. Disponível em: http://www.eumed.net/cursecon/ecolat/br/

COIMBRA, C. H. G.; PERINA, R. A.; FAUSTO, D. A. Viabilidade econômica de um sistema de integração lavoura-pecuária. Revista Ipecege. Piracicaba, v. 1, n. 1, 2015. Doi: 10.22167/r.ipecege.2015.1.63.

CORDEIRO, L.A.M.; VILELA, L.; MARCHÃO, R.L.; KLUTHCOUSKI, J.; JÚNIOR, G.B.M. Integração lavoura-pecuária e integração lavoura-pecuária-floresta: estratégias para intensificação sustentável do uso do solo. Cadernos de Ciência \& Tecnologia. Brasília, v.32, n.1/2, p. 15-53, jan./ago. 2015.

COSTA. C. B.; DE SOUZA, A. L.; CASTELLANI, D. C.; DA SILVA, M. L.; BORGES, E. E. L. Análise de Viabilidade da Produção de Semente e Polpa de Jatobá (Hymenaeaspp) na Região Sul de Goiás. Ciência Florestal, Santa Maria, v. 26, n. 3, p. 1023-1036, jul.-set., 2016.2 Disponível em: http://dx.doi.org/10.5902/1980509824231. Doi: 10.5902/1980509824231.

CUSTÓDIO, G.D.; RIBON, A.A.; FERNANDES, K.L.; HERMÓGENES, V.T.L.; BARROS, L.R. Densidade do solo e densidade relativa - indicadores da qualidade física de um latossolo amarelo sob diferentes manejo de pastagens e mata nativa. Campo Digit@l: Revista Ciências Exatas e da Terra e Ciências Agrárias, v.10, n.1, p. 50-62, 2015.

FERNANDES, M. da S.; FINCO, M. V. A. Sistemas de integração lavoura-pecuaria e políticas de mudanças climáticas. Pesquisa Agropecuaria Tropical. Goiânia, v.44, n.2, p.182-190, 2014.

FERRAZA, R.A.; LOPES, M.A.; ALBUQUERQUE, C.J.B. Avaliação bioeconômica do consórcio de sorgo com diferentes espécies forrageiras para sistema de integração lavoura-pecuária em Nova Porteirinha, MG. Boletim de Industria Animal, Nova Odessa, v. 73, n.2, p.94-102, 2016. Disponível em: http://revistas.bvsvet.org.br/bia/article/view/31208. Doi: http://dx.doi.org/10.17523/bia.v73n2p94.

GARCIA, C.M.P.; ANDREOTTI, M.; TEIXEIRA FILHO, M.C.M.; BUZETTI, S.; CELESTRINO, T.S.; LOPES, K.S.M. Desempenho agronômico da cultura do milho e espécies forrageiras em sistema de Integração Lavoura-Pecuária no Cerrado. Ciência Rural. Santa Maria, v. 43, n.4, 2013.

GLÉRIA, A.A.; SILVA, R.M.; SANTOS, A.P.P.; SANTOS, KJ.G.; PAIM, T.P. Produção de bovinos de corte em sistemas de integração lavoura pecuária. Archivos de Zootecnia. Goiânia, v.66, n.66, p. 141 - 150, 2017.

GONÇALVES, S. L.; FRANCHINI, J. C. Integração lavoura-pecuária. Londrina: Embrapa Soja, 2007. (Circular técnica, 44).

HELMERS, G.; SHAIK, S. Economies of scope and scale efficiency gaints due to diversification, Western Agricultural Economics Association Annual Meeting, Denver, Colorado, p. 1 - 20, 2003. Disponível em: ENCICLOPÉDIA BIOSFERA, Centro Científico Conhecer - Goiânia, v.14 n.25; p.99 2017 
<https://core.ac.uk/download/pdf/6530936.pdf> Acesso em: 07 de dezembro de 2016.

LUCENA, H. D.; PARAENSE, V. C.; MANCEBO, C, H, A. Viabilidade Econômica de um Sistema Agroflorestal com Cacau e Essências Florestais de Alto Valor Comercial em Altamira-PA. Revista de Administração e Negócios da Amazônia, v.8, n.1, jan/abr. 2016. Disponível em: http://www.periodicos.unir.br/index.php/rara/article/view/1566/1524. Doi: 10.18361/2176-8366/rara.v8n1p73-84

MOREIRA, V. R.; BARREIROS, R. F.; PROTIL, R. M. Portfolio de produção agropecuária e gestão de riscos de mercado nas cooperativas do agronegócio paranaense. Revista de Administração. São Paulo, v. 46, n.4, p.325-341, 2011.

PEDERSEN, P.; LAUER, J. G. Influence of rotation sequence and tillage system on the optimum plant population for corn and soybean. Agronomy Journal, v. 94, n. 5, p. 968-971, 2002. Disponível em: https://dl.sciencesocieties.org/publications/aj/abstracts/94/5/968?access=0\&view=pdf DOI:10.2134/agronj2002.9680.

RICHETTI, A.; FLUMIGNAN, D. L.; ALMEIDA, A. C. S. Viabilidade econômica do milho safrinha, sequeiro e irrigado, na Região Sul de Mato Grosso do Sul, para 2016. Comunicado Técnico 207, Dourados, 2015.

RICHETTI, A. Viabilidade Econômica da Cultura da Soja na Safra 2016/2017, em Mato Grosso do Sul. Comunicado Técnico 211, Dourados, 2016.

SANTOS, S.S.; GRZEBIELUCKAS, C. Silvopastoral system with eucalyptus and beef cattle: na economic feasibility analysis on a farm in Mato Grosso/Brazil. Custo e Agronegócio On Line, v. 10, n. 3. p. 317-333, 2014.

SANTOS, G.G.; MARCHÃO, R.L.; SILVA, E.M.; SILVEIRA, P.M.; BECQUER, T. Qualidade física do solo sob sistemas de integração lavoura-pecuária. Pesquisa Agropecuária Brasileira. Brasília, v. 46, n. 10, 2011.

SILVA, A.R.; SALES, A.; VELOSO, C.A.C. Desenvolvimento da soja em sistemas de integração lavoura-pecuária-floresta. Enciclopédia Biosfera, Centro Científico Conhecer. Goiânia, v.11, n.22, p. 896 - 904, 2015. Disponível em: http://www.conhecer.org.br/enciclop/2015c/agrarias/desenvolvimento\%20da \%20soja.pdf Doi: http://dx.doi.org/10.18677/Enciclopedia_Biosfera_2015_129.

SORATTO, R.P.; PEREIRA, M.; COSTA, T.A.M.; LAMPERT, V.N. Fontes alternativas e doses de nitrogênio no milho safrinha com sucessão à soja. Revista Ciência Agronômica. Fortaleza, v.41, n.4, p. 511-518, 2010.

TORRES, J.L.R.; PEREIRA, M.G. Produção e decomposição de resíduos culturais antecedendo milho e soja num latossolo no cerrado mineiro. Comunicata Scienticie. Bom Jesus, v.5, n.4, p.419-426, Out./Dez. 2014.

ZAGO, C. A.; WEISE, A. D.; HORNBURG, R. A. A importância do estudo de viabilidade econômica de projetos nas organizações contemporâneas. In: Congresso 
Virtual Brasileiro de Administração - CONVIBRA, 6., 2009. Anais eletrônicos... Convibra, 2009. Disponível em:

http://www.convibra.com.br/2009/artigos/142_0.pdf> Acesso em: 2017. 